\title{
Bcl-2 gene silencing by RNA interference inhibits the growth of the human gallbladder carcinoma cell line GBC-SD in vitro and in vivo
}

\author{
ZHI-MIN GENG, MIN ZHANG, XIAO-TAO PAN and LIN WANG \\ Department of Hepatobiliary Surgery, First Affiliated Hospital of the Medical College, \\ Xi'an Jiaotong University, Xi'an, Shaanxi 710061, P.R. China
}

Received March 2, 2013; Accepted May 20, 2013

DOI: $10.3892 /$ or.2013.2539

\begin{abstract}
Gallbladder carcinoma is the most common malignant tumor in the biliary system; however, the underlying mechanisms of tumor initiation, progression and metastasis are not fully understood to date. The B-cell lymphoma/ leukemia-2 (Bcl-2) gene, which is highly expressed in gallbladder carcinoma tissue, is one of the most important regulatory factors in cell apoptosis, and plays an important role in the initiation and progression of gallbladder carcinoma. In the present study, we constructed a eukaryotic expression vector of small interference RNA (siRNA) specific to the Bcl-2 gene and transfected it into GBC-SD human gallbladder carcinoma cells. We demonstrated that the constructed $\mathrm{Bcl}-2$ siRNA vector effectively silenced Bcl-2 gene expression in the GBC-SD human gallbladder carcinoma cells, inhibited cell proliferation, induced cell apoptosis, increased chemotherapeutic sensitivity to 5-fluorouracil and inhibited tumor growth in vivo. Collectively, these data reveal an important contribution of Bcl-2 to gallbladder carcinoma. Thus, the use of a synthetic inhibitor of Bcl-2 may be a promising approach for the treatment of gallbladder carcinoma.
\end{abstract}

\section{Introduction}

Gallbladder carcinoma is the most common primary malignancy of the biliary system; it is the fifth most common malignancy of the gastrointestinal tract (GIT). It is characterized by very high invasion and is associated with poor prognosis. Patients with gallbladder carcinoma usually have advanced disease at the time of diagnosis, except for a subset of patients who are diagnosed incidentally at the time

Correspondence to: Professor Zhi-Min Geng, Department of Hepatobiliary Surgery, First Affiliated Hospital of the Medical College, Xi'an Jiaotong University, 277 Yan Ta Xi Lu, Xi'an, Shaanxi 710061, P.R. China

E-mail: gengzhimin@mail.xjtu.edu.cn

Key words: gallbladder carcinoma, RNA interference, B-cell lymphoma/leukemia-2 gene, growth, cell apoptosis of elective cholecystectomy. Despite advances in diagnosis and treatment of gallbladder carcinoma, long-term survival remains dismal. Indeed, chemotherapy and radiotherapy are ineffective as primary treatments, and resection remains the only chance for cure. However, only a minority of patients are candidates for resection at the time of diagnosis. Even after curative resection, most series quote a long-term survival of only 5-12\% (1-3). Thus alternative treatment approaches are required, for example, intervention at the molecular level. However, the underlying mechanisms of tumor initiation, progression and metastasis of gallbladder carcinoma are still not fully understood.

In recent years, molecular biology studies have found genes related to gallbladder carcinoma including $c$-myc, B-cell lymphoma/leukemia-2 (Bcl-2), P53, P16 and Survivin (4-8). The $B c l-2$ gene is one of the most important regulatory factors in cell apoptosis. It can extend cell survival by inhibiting the apoptotic process. Moreover, studies have found that $\mathrm{Bcl}-2$ gene expression is very high in malignant tumor tissues including those derived from gallbladder carcinoma (9-11). These findings indicate that the $\mathrm{Bcl}-2$ gene plays an important role in the initiation and progression of gallbladder carcinoma. Therefore, targeting the $\mathrm{Bcl}-2$ gene may lead to effective treatment for gallbladder carcinoma.

The relatively recent development of RNA interference (RNAi) technology, which has a strong effect on post-transcriptional gene silencing, has been widely used to target oncogenes and inhibit cancer growth $(12,13)$. In the present study, we constructed eukaryotic vectors bearing small interference RNA (siRNA) sequences targeting the $\mathrm{Bcl}$-2 gene. First, the constructs were transfected into the human gallbladder carcinoma GBC-SD cell line and stable transfectants were selected for investigation. We observed that silencing of Bcl-2 resulted in the growth inhibition of gallbladder carcinoma cells and sensitization to chemical drugs, through in vitro and in vivo experiments. Thus, we provide a basis for the treatment of gallbladder carcinoma with $\mathrm{Bcl}-2$ genetic RNAi techniques.

\section{Materials and methods}

Cell line and culture. The human gallbladder carcinoma cell line, GBC-SD, was maintained in the central laboratory of 
the Medical College of Xi'an Jiaotong University. Cells were cultured in RPMI-1640 medium supplemented with $10 \%$ fetal bovine serum (FBS; both from Gibco-BRL, USA) under saturated humidity conditions at $37^{\circ} \mathrm{C}$ in $5 \% \mathrm{CO}_{2}$. Cells were passaged at a 1:2 ratio when the attached cell density reached $\sim 80$ to $90 \%$.

Animals. All animal experiments were reviewed and approved by the Ethics Committee of the First Affiliated Hospital of the Medical College, Xi'an Jiaotong University. BALB/c nude mice, 4-6 weeks of age (weighing 18-22 g) were provided by the laboratory animal center of the Fourth Military Medical University and bred in an SPF grade animal experimental center of the Xi'an Jiaotong University at $25^{\circ} \mathrm{C}$ and $60-70 \%$ humidity. They were fed a standard rodent diet and water.

Design of the specific siRNA targeting Bcl-2. According to the $B c l-2$ mRNA sequence in GenBank and using siRNA Design Software provided by Invitrogen (http://www.invitrogen.com), we chose a target sequence according to the principle of siRNA target sequence design. We then further verified the sequence through the BLAST program from the NCBI (http://www. ncbi.nlm.nih.gov) website. The siRNA sequences that targeted the $\mathrm{Bcl}$-2 gene were as follows: $515 \mathrm{~S}$ sense, 5'-GATCCGCATC GCCCTGTGGATGACTTTCAAGAGA AGTCATCCACAG GGCGATGTTTTTTGGAAA-3'; 515A antisense, 5'-AGC TTTTCCAAAAAACATCGCCCTGTGGATGACTTCTCT TGAAAGTCATCCACAGGGCGATGCG-3'; ConS sense, 5'-GATCCACTACCGTTGTTATAGGTGTTCAAGAGACA CCTATAACAACGGTAGTTTTTTTGGAAA-3'; ConA antisense, 5'-AGCTTTTCCAAAAAAACTACCGTTGTTATAG GTGTCTCTTGAACACCTATAACAACGGTAGTG-3'. The 515S and 515A are sense and antisense strands of DNA containing the interference point sites. ConS and ConA are sense and antisense strands of DNA containing the negative control. The underlined sections in 515S and 515A, ConS and Con A are consistent or opposite complementary sequences with the target gene mRNA and negative sequence, respectively. GAT, GGAAA is the enzyme site, CCG is the recognition site of RNA polymerase III, TTCAAGAGA forms the structure of stem ring, and TTTTTT is the termination signal of transcription. These sequences were connected and reconstructed within the pSilencer ${ }^{\mathrm{TM}}$-EGFP vector (Department of Biochemistry and Molecular Biology of the Fourth Military Medical University), then transfected and integrated into the eukaryotic cell genome. Finally, shRNAs were transcribed out from the initiation site recognized by the RNA polymerase III.

Construction and identification of the Bcl-2 siRNA eukaryotic expression vector. After annealing the synthetic oligonucleotides, pSilencer ${ }^{\mathrm{TM}}$-EGFP was cut with BamHI and HindIII enzymes (Gibco-BRL, USA). The plasmid was inoculated into freeze-stored DH5 $\alpha$ (Department of Biochemistry and Molecular Biology of the Fourth Military Medical University) and then cultivated on a plate, without antibiotics, at $37^{\circ} \mathrm{C}$ overnight. The following day, monoclonal colonies were selected and inoculated in $10 \mathrm{ml}$ of LB culture solution without antibiotics, and cultured at $37^{\circ} \mathrm{C}$ with agitation at $250 \mathrm{rpm}$ overnight. The next day $1 \%$ of the culture was transferred into $200 \mathrm{ml}$ of non-antibiotic containing LB culture solution and agitated for a further $2 \mathrm{~h}$. The culture was stopped when the solution absorbance at $\mathrm{A}_{260}$ was 0.4 . The bacterial culture was then placed on ice for $30 \mathrm{~min}$, followed by centrifugation at 5,000 rpm for $10 \mathrm{~min}$ at $4^{\circ} \mathrm{C}$. The supernatant was then removed and the cells were retrieved. The precipitate was resuspended in TSS under aseptic conditions; it was then frozen at $-70^{\circ} \mathrm{C}$ until use. The recycling products and annealing products were connected at $4^{\circ} \mathrm{C}$ overnight. The connection was added to $100 \mu 1$ of competent cells and shaken slightly, incubated on ice for $30 \mathrm{~min}$, then placed in a $42^{\circ} \mathrm{C}$ water bath for $90 \mathrm{sec}$, followed by cooling for 2-3 min. Two hundred microliters of preheated no penicillin (Amp) LB medium was then added to each tube, then agitated slowly at $140-150 \mathrm{rpm}$ for $45 \mathrm{~min}$ at $37^{\circ} \mathrm{C}$ to promote bacterial recovery. The transformed competent cells were smeared onto an agar plate that contained antibiotic until the liquid was completely absorbed. Then, the plate was inverted and cultured for $12-16 \mathrm{~h}$ at $37^{\circ} \mathrm{C}$ until the colonies appeared. Six colonies were randomly selected from each group. The plasmid was extracted with the 'small kit' from Shanghai HuaShun Company, according to the instructions.

Three microliters of extracted plasmid DNA was cut with the BamHI and HindIII enzyme and cultured for $3 \mathrm{~h}$ at $37^{\circ} \mathrm{C}$. The digested products were separated on a $1 \%$ agarose gel by electrophoresis and then photographed under a UV transilluminator. The positive clones identified by enzyme digestion were sent to Beijing Augct DNA-Syn Biotechnology Co., Ltd. for sequence testing. Recombinant plasmids were named pSilencer ${ }^{\mathrm{TM}}$-EGFP sh515 (experimental group) and pSilencer ${ }^{\mathrm{TM}}$-EGFP shCon (negative control group).

Transfection of GBC-SD cells with Bcl-2 siRNA. GBC-SD cells in the logarithmic growth phase were inoculated into a 6-well plate at a concentration of $2 \times 10^{5}$ cells/well. Transfection by a liposome-mediated DNA method using Lipofectamine 2000 (Invitrogen, Gaithersburg, USA) was performed 24-48 h when the culture confluence reached $80 \%$ in accordance with the instruction. The experiment was divided into two groups transfected with either pSilencer ${ }^{\mathrm{TM}}$-EGFP sh515 (experimental group) or pSilencer ${ }^{\mathrm{TM}}$-EGFP shCon (negative control group).

The culture solution of transiently transfected GBC-SD cells was replaced every 2-3 days. The cells began to die after two days when treated with G418, whose screening concentration was $400 \mu \mathrm{g} / \mathrm{ml}$. Positive clones were observed in 2 weeks. Thereafter, the cloned cells did not appear to die in the presence of G418 (400 $\mu \mathrm{g} / \mathrm{ml})$, but their growth was slow. A visible cloning cell was formed in $\sim 6-8$ weeks. The monoclone was selected for further expansion in culture. The experiment was divided into the experimental group and the negative control group.

Reverse transcription-polymerase chain reaction ( $R T-P C R)$. GBC-SD human gallbladder carcinoma cells were transiently transfected with pSilencer ${ }^{\mathrm{TM}}$-EGFP vector and the negative control empty vector, and the cells of each group were collected $12 \mathrm{~h}$ later for total RNA extraction using TRIzol reagent (Invitrogen). Eight microliters of RNA was used to synthesize cDNA and then subjected to PCR amplification. PCR primers were synthesized by Beijing Augct DNA-Syn Biotechnology Co., Ltd. The $B c l-2$ primer sequences were as follows: upstream primer 5'-CTGGGAGAACAGGGTACGATAA-3', 
downstream primer 5'-AGCCAGGAGAAATCAAACA GAG-3', resulting in a PCR product of $210 \mathrm{bp} . \beta$-actin was amplified as a control using the following primer sequences: upstream 5'-TGCGCAGAAAACAAGATGATT-3' and downstream 5'-TGGGGGACAAAAAGGGGGAAGG-3', resulting in a PCR product of $450 \mathrm{bp}$. The PCR conditions were: one cycle of denaturing at $94^{\circ} \mathrm{C}$ for $30 \mathrm{sec}$ (first cycle was $94^{\circ} \mathrm{C}$ for $4 \mathrm{~min}$ ), annealing at $60^{\circ} \mathrm{C}$ for $30 \mathrm{sec}$, extension at $72^{\circ} \mathrm{C}$ for $30 \mathrm{sec}$, followed by 25 cycles. $\beta$-actin cDNA was amplified at the same time as an internal standard control. The PCR products were loaded onto a $1 \%$ agarose gel for electrophoresis. The stably transfected GBC-SD cells were also tested for knockdown of $B c l-2$ with RT-PCR.

Western blotting. The GBC-SD cells were transfected with recombinant plasmid vectors of the two groups and harvested $12 \mathrm{~h}$ later. The total cell protein was extracted with the RIPA total protein kit (Santa Cruz Biotechnology, Inc., USA) and quantified with the $\mathrm{ABC}$ protein quantification method. The sample was separated by SDS-PAGE (12\%) and transferred onto a nitrocellulose membrane. The western blot analysis method was used to detect $B c l-2$ protein expression using rabbit anti-human $\mathrm{Bcl}-2$ polyclonal antibody (AB1720; Chemicon, USA). Detection was performed with an enhanced chemiluminescence agent. The expression of $\beta$-actin was tested as an internal standard control. The stably transfected GBC-SD cells were also tested for Bcl-2 protein expression using the same method.

Cell growth and proliferation assay. GBC-SD cells were transfected transiently with the vector of each group and digested $12 \mathrm{~h}$ later. The cells were inoculated into a 96-well plate at a concentration of $5 \times 10^{3}$ cells/well. A concentration of $10 \mu \mathrm{mol} / 1$ Ponasterone A was added to each well as an inducer. A further $20 \mu 1$ of freshly prepared MTT $(0.5 \mathrm{mg} / \mathrm{ml})$ (Sigma, USA) was added to different wells at 12,24,36, 48 and $60 \mathrm{~h}$ later, respectively. The cells were cultured at $37^{\circ} \mathrm{C}$ for $4 \mathrm{~h}$, then MTT liquid was removed and $150 \mu 1$ DMSO (Sigma, USA) was added to each well. Optical density (OD) readings were obtained at $490 \mathrm{~nm}$, from which the inhibition rate of tumor cell growth was calculated using the formula: Inhibition rate $=$ (average absorbance (A) value of control group - average A value of experimental group)/average A value of control group x $100 \%$.

Flow cytometric apoptosis assay. Apoptotic cells were determined using the Annexin V/fluorescein isothiocyanate (FITC) Apoptosis Detection kit (Jingmei Biotech Co., Shenzhen, China) and an EPICS XL-MCL flow cytometer (Becton-Dickinson) according to the manufacturer's instructions. Briefly, GBC-SD cells, and cells stably transfected with either GBC-SD-RNAi pSilencer ${ }^{\text {TM }}$-EGFP shCon or GBC-SD-RNAi pSilencer ${ }^{\mathrm{TM}}$-EGFP sh515 were collected and single cell suspensions $\left(1 \times 10^{6}\right.$ cells) were prepared. Briefly, $1 \times 10^{6}$ cells were stained with Annexin V/FITC for $30 \mathrm{~min}$ at $4^{\circ} \mathrm{C}$ in the dark and then stained with propidium iodide for 10 min before flow cytometric analysis.

Chemotherapy drug sensitivity assay. The number of living cells was counted by the trypan blue staining method and used to adjust the number of cells to $5 \times 10^{5} / \mathrm{ml}$. The cells were inocu- lated into a 96-well plate in a volume of $100 \mu \mathrm{l} /$ well and cultured for $24 \mathrm{~h}$ in an incubator with $5 \% \mathrm{CO}_{2}$ and saturated humidity at $37^{\circ} \mathrm{C}$. A volume of $25 \mu \mathrm{l}$ of different drugs was added into the experimental wells: $1 \mu \mathrm{g} / \mathrm{ml}$ 5-fluorouracil (5-FU; Tianjin Jinyao Amino Acid Co., Ltd.), $0.3 \mu \mathrm{g} / \mathrm{ml}$ mitomycin C (MMC; Hebei QiYuan Pharmaceuticals Corp.), $0.04 \mu \mathrm{g} / \mathrm{ml}$ adriamycin (ADM; Zhejiang HaiZheng Pharmaceutical Co., Ltd.) and $0.3 \mu \mathrm{g} / \mathrm{ml}$ cisplatin (DDP; Shandong Luoxin Pharmaceutical Co., Ltd.) (drug concentration was subjected to $1 / 10$ of blood concentration), while the same amount of PBS was added into the control wells. The medium was removed after cultivation for $48 \mathrm{~h}$, and $25 \mu \mathrm{l}$ of freshly prepared MTT solution $(2 \mathrm{mg} / \mathrm{ml})$ was added into each well. The supernatant was removed after cultivation for $6 \mathrm{~h}$ at $37^{\circ} \mathrm{C}$, and $150 \mu \mathrm{l}$ of DMSO was added to each well. OD readings of each well were measured at $570 \mathrm{~nm}$ when the purple crystals were dissolved completely, with $630 \mathrm{~nm}$ as a reference wavelength. The inhibition rate was calculated using the following formula: Inhibition rate $(\%)=(1-$ average OD value of the experimental well/average OD value of the control well) $x 100$.

\section{In vivo tumorigenicity assay}

In vivo tumorigenicity assay. Twelve nude mice, 4-6 weeks of age, were randomly divided into the $B c l-2$ siRNA experimental and control groups $(\mathrm{n}=6)$. For the experimental group, Bcl-2 siRNA stably transfected GBC-SD suspensions of $6 \times 10^{6}$ cells in $0.2 \mathrm{ml}$ were subcutaneously injected into the left flank of nude mice. For the control group, GBC-SD suspensions alone of $6 \times 10^{6}$ cells in $0.2 \mathrm{ml}$ were injected into the left flank of nude mice.

Gene therapy studies. The human gallbladder carcinoma xenograft nude mouse model was generated. Briefly, 18 BALB/c nude mice, 4-6 weeks of age, were injected with a total number of $6 \times 10^{6} \mathrm{GBC}-\mathrm{SD}$ cells/mouse into the right flank. The 18 mice were randomly divided into three groups: pSilencer ${ }^{\mathrm{TM}}$-EGFP sh515 group (experimental group), pSilencer ${ }^{\mathrm{TM}}$-EGFP shCon group (empty vector negative control group) and the normal control group. Next, $10 \mu \mathrm{g}$ recombinant DNA plasmid pSilencer ${ }^{\mathrm{TM}}$-EGFP sh515 and pSilencer ${ }^{\mathrm{TM}}$-EGFP shCon (negative control) were each mixed with $30 \mu \mathrm{l}$ Lipofectamine 2000 liposome (Invitrogen), and then they were injected into multiple sites of peritumoral tissue of the mice every 2 days for a total of five injections.

Observation of xenograft tumor growth. The general condition of the nude mice was observed every day, while tumor size was measured every 4 days. The tumor size was calculated according to the formula: $\mathrm{V}=\pi \mathrm{a}^{2} \mathrm{~b} / 6$ (a, tumor short diameter; $\mathrm{b}$, tumor long diameter) and the growth rate was calculated according to the formula: Average growth rate $=$ mean tumor volume $(\mathrm{mm})^{3} /$ host with tumor time (days), and tumor growth curves were drawn. Mice were sacrificed after 6 weeks, and the tumors were removed and weighed. The liver, lung, spleen, kidney and other organs were also removed. All were fixed in $10 \%$ (volume fraction) formaldehyde solution, paraffin embedded, and then cut into 4- to 5- $\mu \mathrm{m}$ sections for histological study. The sections from the tumor were stained with $B c l-2$ by immunohistochemistry or with $\mathrm{H} \& \mathrm{E}$ staining, in order to investigate tumor metastasis and side effects. 


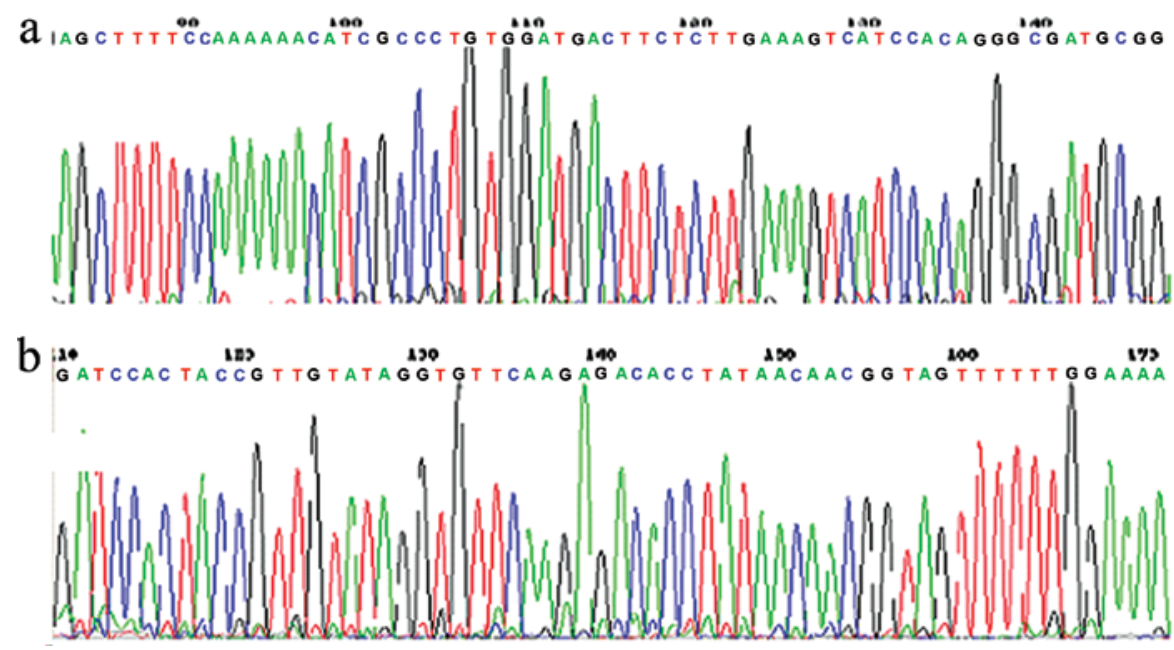

Figure 1. The sequencing diagram of the recombinant pSilencer ${ }^{\mathrm{TM}}$-EGFP vector. (a) pSilencer ${ }^{\mathrm{TM}}$-EGFP sh515; (b) pSilencer ${ }^{\mathrm{TM}}$-EGFP shCon.

Statistical analysis. The data are expressed as mean \pm standard deviation (SD). Statistical significance was determined using the $\chi^{2}$ test and Student's t-test. A value of $\mathrm{P}<0.05$ was considered to indicate a statistically significant difference. SPSS 13.0 for Windows (SPSS, Inc., Chicago, IL, USA) was used for statistical analyses. All statistical tests were twotailed.

\section{Results}

DNA sequencing and identification of the Bcl-2 siRNA recombinant plasmid vector. The results of DNA sequencing, from Beijing Augct DNA-SYN Biotechnology Co., Ltd., showed that the sequence of the vector was identical to the designed sequence, indicating that the recombinant plasmid vector was constructed successfully (Fig. 1). The recombinant plasmid which contained the shRNA coding sequence was named pSilencer $^{\mathrm{TM}}$-EGFP sh515 (experimental group) and the empty vector was referred to $\mathrm{pSilencer}^{\mathrm{TM}}$-EGFP shCon (negative control group). Both plasmids were amplified for future study.

\section{In vitro studies}

Effect of Bcl-2 siRNA transfection into GBC-SD cells. The expression of each plasmid was confirmed by fluorescence microscopy $12 \mathrm{~h}$ after transfection of cells. Ten fields of view were chosen in each group (experimental and control), from which the number of green fluorescent-positive cells and the total number of cells were calculated. The transfection efficiency was calculated in accordance with the formula: Transfection efficiency $=$ (number of green fluorescentpositive cells/total number of cells) x $100 \%$. Experiments were repeated three times. The result showed that there was no fluorescence signal in pSilencer ${ }^{\mathrm{TM}}$-EGFP shCon (negative control group) after its transient transfection into human gallbladder carcinoma GBC-SD cells, but the transfection rate of pSilencer ${ }^{\mathrm{TM}}$-EGFP sh515 (experimental group) varied between 45 and $70 \%$ (Fig. 2a). After stable transfection with pSilencer $^{\mathrm{TM}}$-EGFP into GBC-SD cells, as before, the fluorescence test showed no fluorescent signals in the negative control group, but there was readily detectable fluorescence in the experimental groups for which the transfection rate was
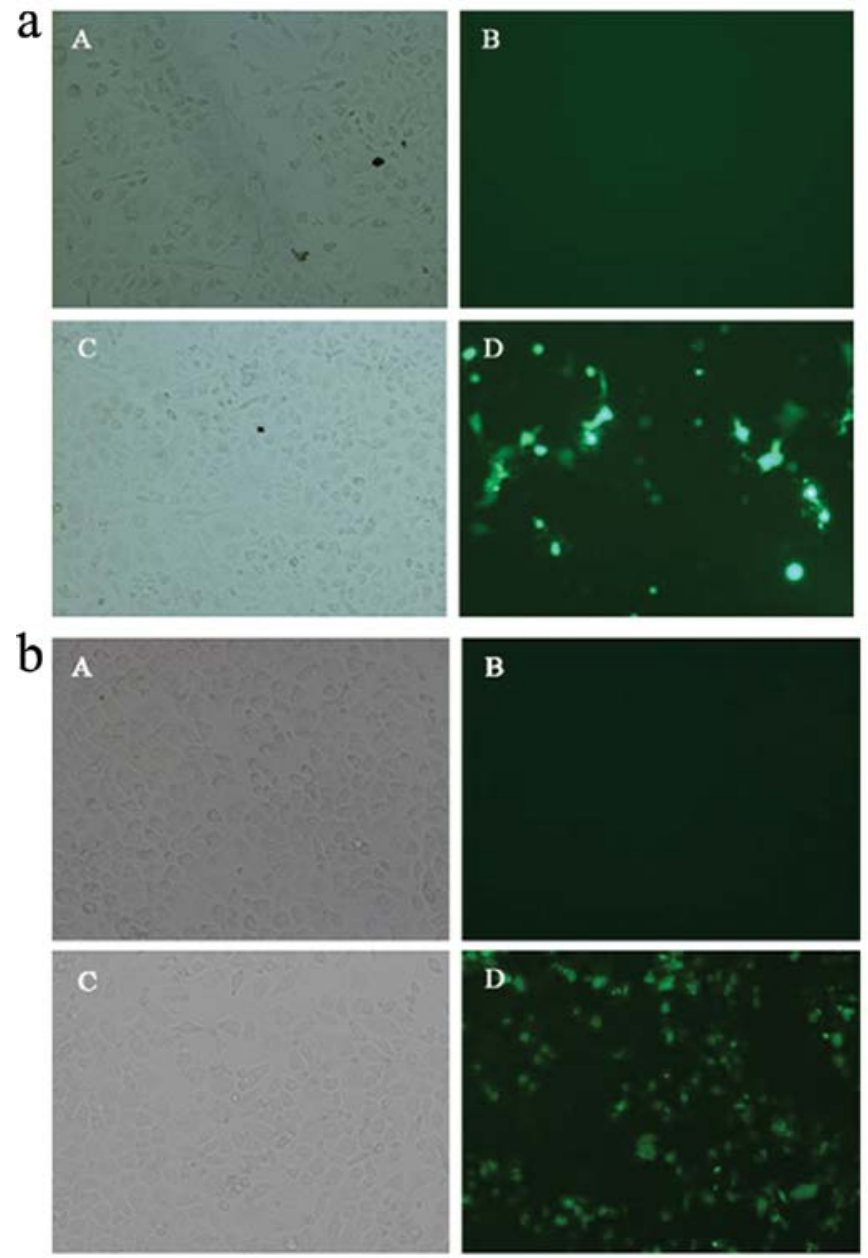

Figure 2. Effect of B-cell lymphoma/leukemia-2 (Bcl-2) small interference RNA (siRNA) transfection into GBC-SD cells. (a) The effect of transient transfection of $\mathrm{Bcl}-2$ siRNA into GBC-SD cells (x100). (b) The effect of stable transfection of $B c l-2$ siRNA into GBC-SD cells (x100). A and B: pSilencer ${ }^{\mathrm{TM}}$-EGFP shCon (negative control group); $\mathrm{C}$ and D: pSilencer ${ }^{\mathrm{TM}}$-EGFP sh515 (experimental group).

nearly $100 \%$. This confirmed that the GBC-SD cells had been stably transfected with pSilencer ${ }^{\mathrm{TM}}$-EGFP (Fig. 2b). 


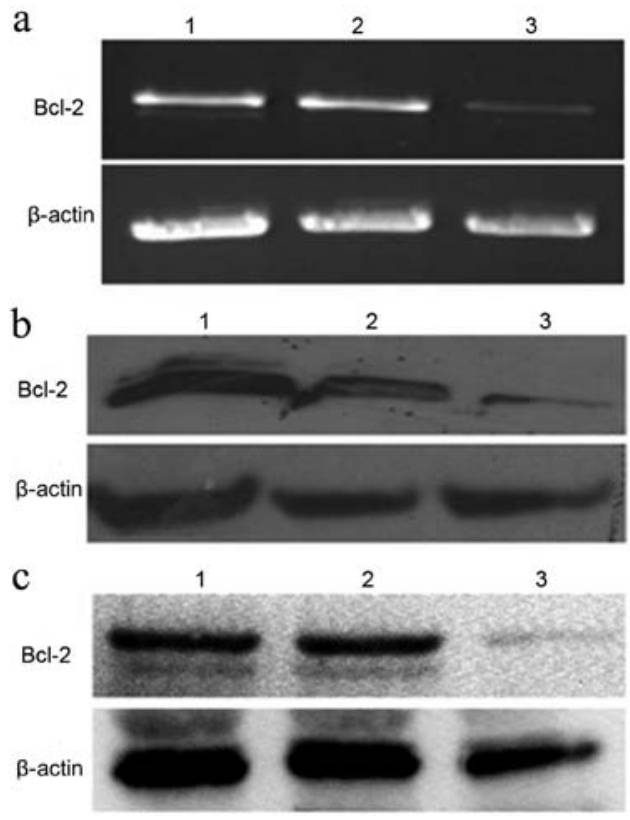

Figure 3. B-cell lymphoma/leukemia-2 (Bcl-2) small interference RNA (siRNA) inhibits $B c l-2$ mRNA expression and protein expression. (a) Bcl-2 mRNA expression after transient transfection with $B c l-2$ siRNA. $\beta$-actin mRNA levels were measured as a control for input. (b) $B c l$-2 protein expression after transient transfection with $\mathrm{Bcl}-2$ siRNA in GBC-SD cells. (c) $\mathrm{Bcl}$-2 protein expression after stable transfection of GBC-SD with $B c l-2$ siRNA $\beta$-actin protein expression was determined as a control for input. Lane 1, non-transfected; lane 2, pSilencer ${ }^{\mathrm{TM}}$-EGFP shCon; lane 3, pSilencer ${ }^{\mathrm{TM}}$ EGFP sh515.

Bcl-2 siRNA inhibits Bcl-2 mRNA expression. Twelve hours after transient transfection of GBC-SD cells with the recombined pSilencer ${ }^{\mathrm{TM}}$-EGFP vector, or the negative control empty vector, we observed significant inhibition of $\mathrm{Bcl}-2$ mRNA expression in the pSilencer ${ }^{\mathrm{TM}}$-EGFP sh515 experimental group when compared with those of the blank control and pSilencer ${ }^{\mathrm{TM}}$-EGFP shCon groups (Fig. 3a).

Bcl-2 siRNA inhibits Bcl-2 protein expression. Twelve hours after transient transfection of GBC-SD cells with pSilencer $^{\mathrm{TM}}$-EGFP sh515 or pSilencer ${ }^{\mathrm{TM}}$-EGFP shCon, protein lysates were collected and tested by western blot analysis for $\mathrm{Bcl}-2$ expression. The results showed that $\mathrm{Bcl}-2$ protein expression in the pSilencer ${ }^{\mathrm{TM}}$-EGFP sh515 experimental group was significantly reduced when compared with that of the pSilencer ${ }^{\mathrm{TM}}$-EGFP shCon negative control group or the non-transfected (blank) group, consistent with RT-PCR results (Fig. 3b). Similar results were also obtained using protein lysates prepared from the stably transfected GBC-SD cells (Fig. 3c).

Bcl-2 siRNA inhibits cell growth and proliferation in $G B C-S D$ cells. Twelve hours after transfecting GBC-SD cells with Bcl-2 siRNA, the activity of cells was detected every $12 \mathrm{~h}$ using the MTT method. Data analysis revealed that cell proliferation decreased significantly $(\mathrm{P}<0.05)$ after silencing of $\mathrm{Bcl}-2$, as determined by comparing the cell activity of the pSilencer ${ }^{\mathrm{TM}}$-EGFP sh515 experimental group to either the negative control group (pSilencer ${ }^{\mathrm{TM}}$-EGFP shCon) or the non-transfected blank control group. There was no significant difference in the cellular activity between the two latter groups $(\mathrm{P}>0.05)$ (Fig. 4). The results showed that pSilencer ${ }^{\mathrm{TM}}$-EGFP sh515 silenced the $\mathrm{Bcl}-2$ gene in the GBC-SD human gallbladder carcinoma cells effectively and inhibited the growth and proliferation of the tumor cells.

Bcl-2 siRNA induces GBC-SD cell apoptosis. To further study the effect of $\mathrm{Bcl}-2$ siRNA on GBC-SD cell apoptosis, cells were stained with Annexin V-FITC and propidium iodide. As shown in Fig. 5, the apoptotic percentage of GBC-SD/Bcl-2 siRNA cells was $30.83 \pm 4.2 \%$, which was significantly higher than that of the GBC-SD/Bcl-2 negative control $(4.3 \pm 1.3 \%)$ and GBC-SD cells $(3.6 \pm 1.1 \%)(\mathrm{P}<0.05)$. This implies that inhibition of $\mathrm{Bcl}-2$ is able to induce apoptosis in gallbladder cancer GBC-SD cells.

Bcl-2 siRNA increases sensitivity of GBC-SD cells to chemotherapy drugs. Four types of chemotherapy drugs were diluted into the following concentrations: 5-FU $1 \mu \mathrm{g} / \mathrm{ml}$; MMC $0.3 \mu \mathrm{g} / \mathrm{ml}$; ADM $0.04 \mu \mathrm{g} / \mathrm{ml}$; DDP $0.3 \mu \mathrm{g} / \mathrm{ml}$, and their inhibitory rates on cells with and without silencing of $B c l-2$ were calculated. The results showed that the sensitivity of gallbladder carcinoma cells to the 4 drugs was increased to different levels after stable transfection with $\mathrm{Bcl}-2$ siRNA stably. However, only the results of the 5-FU group were of statistical significance $(\mathrm{P}<0.05)$, while there were no significant differences between the other groups $(\mathrm{P}>0.05)$ (Fig. 6).

\section{In vivo studies}

RNAi targeting Bcl-2 inhibits tumorigenicity in vivo

Xenograft tumor growth. The tumorigenicity of the control group and $\mathrm{Bcl}$-2 siRNA experimental group were 100 and $60 \%$, respectively. The average volume of tumors was 1914.6 \pm 125.0 and $629.7 \pm 78.9 \mathrm{~mm}^{3}$ in the control and experimental group, respectively. The average growth rate was 45.58 and $14.99 \%$ in the control and experimental group, respectively. The average weight of tumors was $2.24 \pm 0.33$ and $0.77 \pm 0.12 \mathrm{~g}$, in the control and experimental group, respectively. Thus, the average volume, average growth rate and average weight of tumors in the control group were significantly greater than those of the Bcl-2 siRNA group ( $\mathrm{P}<0.05)$ (Fig 7a).

Histopathological changes. H\&E staining of different organs from nude mice showed necrosis of the tumors while the other organs were normal. $\mathrm{Bcl}-2$ immunohistochemical staining showed that the control group expression was stronger with a positive expression rate of $50.4 \pm 1.3 \%$. The $\mathrm{Bcl}-2$ staining in the experimental group was weaker than that in the control group with a positive expression rate of $28.2 \pm 2.1 \%$. This difference was significant between the two groups $(\mathrm{P}<0.05)$ (Fig. 7b).

\section{RNAi targeting Bcl-2 inhibits tumor growth in vivo}

Growth of xenograft tumor. The average volume, average growth rate and average weight of experimental group tumors were significantly lower than those determined for the empty vector negative control and normal control groups $(\mathrm{P}<0.05)$. There was no significant difference when the empty vector negative control group and the normal control group were compared $(\mathrm{P}>0.05)$ (Fig. 7c). 

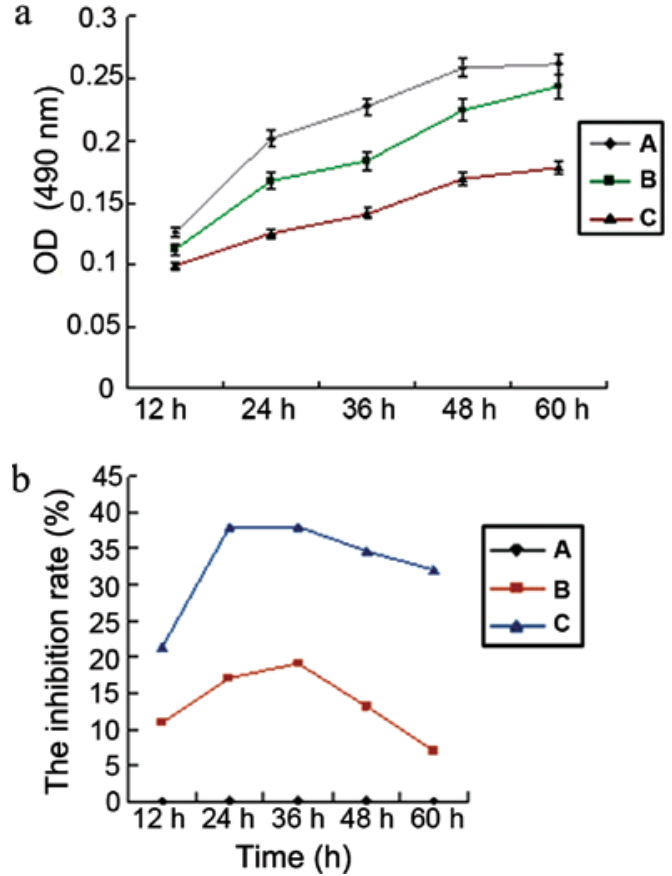

Figure 4. B-cell lymphoma/leukemia-2 (Bcl-2) small interference RNA (siRNA) inhibits cell growth and proliferation. (a) The growth curve of GBC-SD cells transfected with $B c l-2$ siRNA. (b) The inhibition rate of GBC-SD cells transfected with $\mathrm{Bcl}-2$ siRNA. A, non-transfected; B, pSilencer ${ }^{\mathrm{TM}}$-EGFP shCon; C, pSilencer ${ }^{\mathrm{TM}}$-EGFP sh515.

Histopathological changes. H\&E staining of different organs from nude mice showed necrosis of the tumors while other organs were normal. $B c l-2$ immunohistochemical staining results showed that the $\mathrm{Bcl}$-2-positive expression rate in tumors of the empty vector negative control group and the control group was $51.2 \pm 2.3$ and $53.0 \pm 1.7 \%$, respectively; there was no significant difference between these two groups ( $\mathrm{P}>0.05)$. The $B c l-2$ staining in the experimental group was the weakest with a positive expression rate of $34.5 \pm 2.8 \%$, which was significantly lower than the other two groups $(\mathrm{P}<0.05)$ (Fig. 7d).

\section{Discussion}

In recent years, molecular biology research has showed that primary gallbladder carcinoma results from the different effects of polygenes, as well as genetic and environmental carcinogenic factors $(14,15)$. The $B c l-2$ gene is one of the most important regulatory factors in cell apoptosis which plays an important role in the initiation and progression of gallbladder carcinoma. The $\mathrm{Bcl}-2$ gene was first discovered from chromosome fragment sites in follicle type human non-Hodgkin's B lymphoma by Tsujimoto et al (16), thus it was called $B c l-2$. $B c l-2$ protein, one of the $B c l-2$ protein family members, is an important gene which inhibits cell apoptosis. At present, it is believed that the $\mathrm{Bcl}-2$ gene inhibits cell apoptosis through blocking many pro-apoptotic factors. The normal $\mathrm{Bcl}-2$ gene, which has three exons and two promoters and is $\sim 230 \mathrm{~kb}$, is located in chromosome 18q21.3. There is an intron of $\sim 225 \mathrm{~kb}$ between exons 1 and 2, and the length of the intron between exons 2 and 3 is $\sim 370 \mathrm{~kb}$. The $B c l-2$ gene acts at the end of the apoptotic pathway. Its actions include blocking digestion of DNA by endonuclease, influencing DNA repair, blocking apoptosis proteins induced by DNA damage or directly acting on these proteins to render them ineffective. In addition, $B c l-2$ protein coded by the gene can inhibit normal programmed cell death and stimulate the occurrence of tumors with overgrowth. Research has shown that the $B c l-2$ gene is highly expressed in a variety of malignant tumors. Indeed, the $\mathrm{Bcl}-2$ gene is highly expressed and the $\mathrm{Bcl}-2$ protein positive expression rate is $23.4-51.7 \%$ in gallbladder carcinoma (5). The expression in gallbladder carcinoma is much higher than that in gallbladder adenoma and the $\mathrm{Bcl}-2$ gene expression level in poorly differentiated gallbladder carcinoma is higher than that in well-differentiated gallbladder carcinoma. The $\mathrm{Bcl}-2$ protein expression level in the early stage of gallbladder carcinoma is higher than that in the progressive stage. The apoptosis index (AI) and ratio of $\mathrm{AI} /$ proliferation index (MI) are higher in Bcl-2-negative gallbladder carcinoma compared with positive tumors. This suggests that the $B c l-2$ gene, which is a prospective target gene, plays an important role in the initiation and progression of gallbladder carcinoma.

RNAi technology is a type of post transcriptional gene silencing phenomenon, that uses sequence-specific small molecule RNA to identify target mRNA, and then cleaves in the specific site via the protein complex RISC. This leads to specific mRNA degradation and eventual blockage of target gene expression. Its characteristics include high efficiency, specificity, ease and rapidity. It can block target genes, similarly to the effect of gene knockout (17). This technology has been used widely and has promoted research on gene function. RNAi technology has already been applied to a variety of malignant tumor gene therapies and has obtained better results in diseases such as chronic lymphoma and breast cancers $(18,19)$. However, it is still used in the experimental stages of gallbladder carcinoma therapy.

In our study, after successfully constructing the $B c l-2 \mathrm{RNAi}$ vector, we introduced it into human gallbladder GBC-SD cells through both transient and stable transfection. The mRNA and protein expression levels of the $\mathrm{Bcl}-2$ gene were tested by RT-PCR and western blot analysis. The results showed that the vector significantly inhibited $\mathrm{Bcl}-2 \mathrm{mRNA}$ transcription and protein translation.

The growth and proliferation of gallbladder carcinoma cells transfected with $\mathrm{Bcl}-2$ siRNA were tested by MTT method. The results showed that GBC-SD cell proliferative ability was significantly decreased after $B c l-2$ gene silencing. The inhibition of cell growth was time-dependent. Indeed, although the growth of GBC-SD cells was inhibited at each tested time, the strongest inhibitory effects were observed at 24 and $36 \mathrm{~h}$ after transfection, with inhibition rates of $38.12 \pm 0.48$ and $38.08 \pm 0.75$, respectively. The inhibition rate began to decrease after 48 and $60 \mathrm{~h}$ with inhibition rates of $34.67 \pm 0.63$ and $31.98 \pm 0.52$, respectively.

Cell apoptosis was analyzed by flow cytometry. The results showed that the apoptotic percentage of GBC-SD $/ B c l-2$ siRNA cells was $30.83 \pm 4.2 \%$, which was significantly higher than that of the GBC-SD/Bcl-2 negative control $(4.3 \pm 1.3 \%)$ and GBC-SD cells $(3.6 \pm 1.1 \%)(\mathrm{P}<0.05)$. This confirms that the $B c l-2$ protein is an important gene which inhibits cell apoptosis and that inhibition of $\mathrm{Bcl}-2$ is able to induce apoptosis in gallbladder cancer GBC-SD cells. 

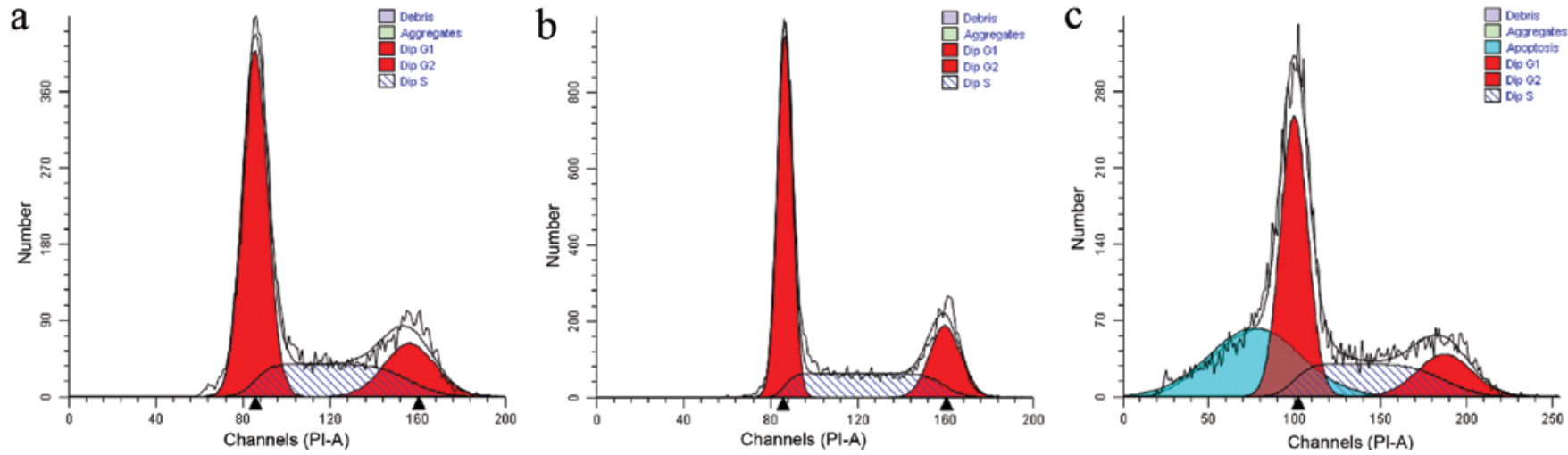

Figure 5. B-cell lymphoma/leukemia-2 ( $B c l$-2) small interference RNA (siRNA) induces cell apoptosis. The apoptotic rate of GBC-SD cells transfected with $\mathrm{Bcl}$-2 siRNA. The percentage of apoptotic cells was analyzed by flow cytometry. (a) Non-transfected; (b) pSilencer ${ }^{\mathrm{TM}}$-EGFP shCon; (c) pSilencer ${ }^{\mathrm{TM}}$ EGFP sh515.

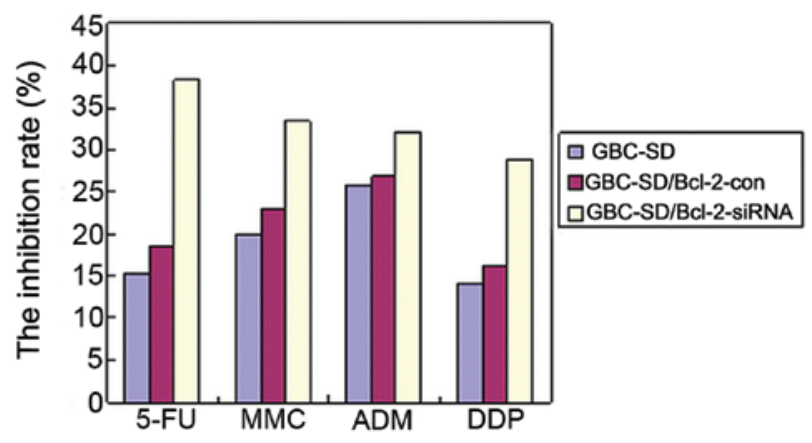

Figure 6. B-cell lymphoma/leukemia-2 ( $B c l-2$ ) small interference RNA (siRNA) increases sensitivity of GBC-SD cells to chemotherapy drugs. The inhibition rate of the 4 chemotherapy drugs to GBC-SD cells transfected with $B c l$-2 siRNA. 5-FU, fluorouracil; MMC, mitomycin C; ADM, adriamycin; DDP, cisplatin.
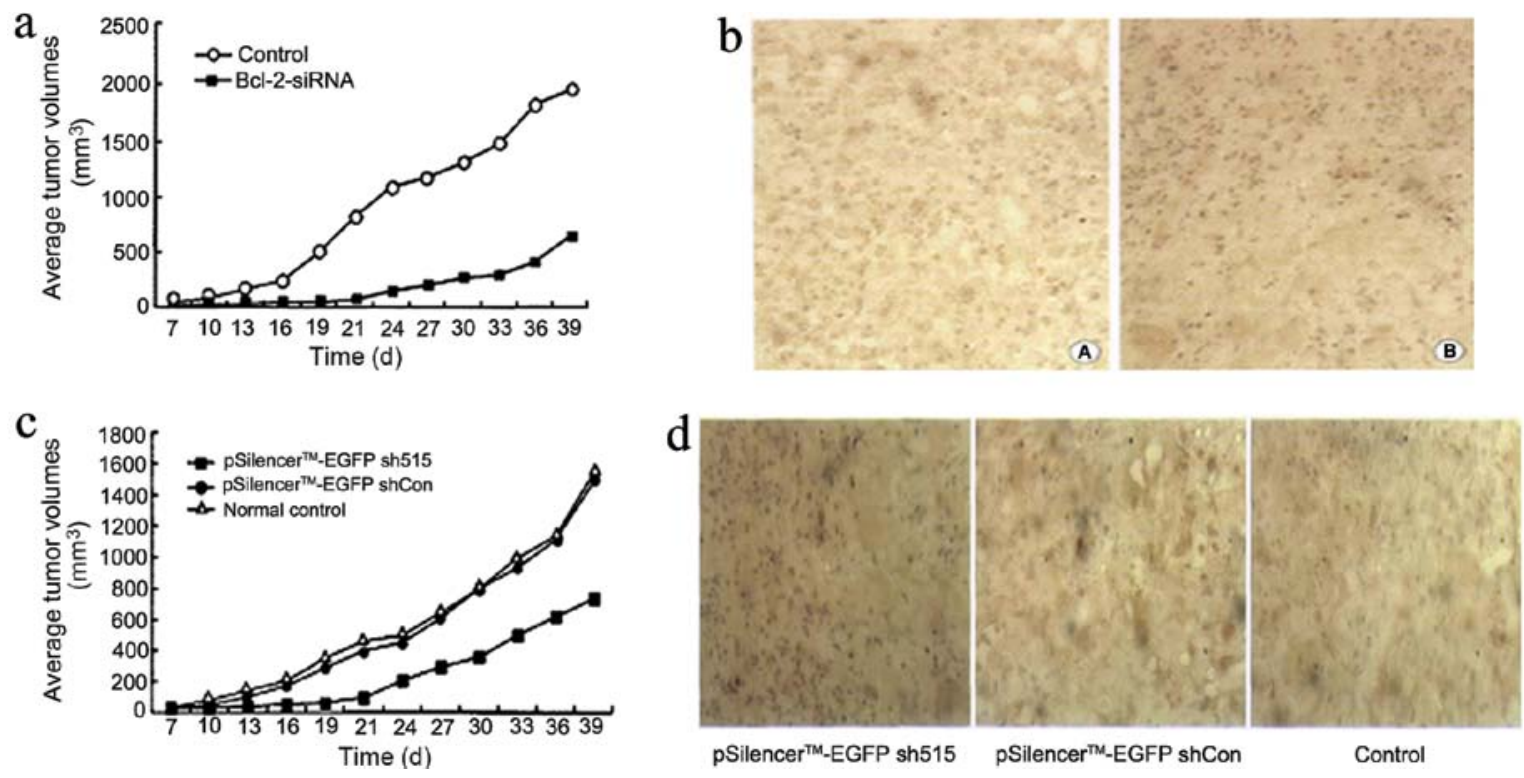

Figure 7. RNA interference (RNAi) targeting B-cell lymphoma/leukemia-2 (Bcl-2) inhibits tumorigenicity and tumor growth. (a) Tumor growth curves of the two groups after injection of GBC-SD cells. (b) Bcl-2 expression in xenograft tumor tissues of the two groups (SP, x200). A, control group; B, experimental group. (c) Tumor growth curves of the three groups after injection of GCB-SD cells. (d) Bcl-2 expression in xenograft tumor tissues (SP, x400).

We further detected the sensitivity of Bcl-2 siRNA transfected gallbladder carcinoma cells to 4 types of commonly used chemotherapy drugs (5-FU, MMC, ADM and DDP). The results showed that the sensitivity of gallbladder carcinoma cells to the 4 drugs increased to different extents after $B c l-2$ gene silencing, but only the results of the 5-FU group were 
statistically significant $(\mathrm{P}<0.05)$. There were no significant differences between the other groups. Thus, these data provide strong evidence that gene therapy targeting $\mathrm{Bcl}-2$ in gallbladder carcinoma can enhance chemotherapeutic efficiency.

A subcutaneous gallbladder carcinoma xenograft nude mouse model was designed for the tumorigenicity assay. The results showed that the tumorigenicity of the control group was $100 \%$, indicating highly malignant and oncogenic abilities of gallbladder carcinoma. In contrast, the results showed that after transfecting GBC-SD cells with $\mathrm{Bcl}$-2 siRNA, oncogenic abilities significantly decreased, and the average volume, average growth rate, and average weight of the experimental group tumors were all significantly lower than those of the control group. The results of $B c l-2$ siRNA therapy showed that local injection with the recombinant plasmid of the $B c l-2$ siRNA vector inhibited the growth of GBC-SD cell tumor xenografts in nude mice. In order to overcome the disadvantage of siRNA degradation in vivo, we injected it at multiple sites. However, although we found that siRNA expressed by the plasmid vector inhibited the growth of tumors in nude mice when compared with the empty plasmid vector, the tumor growth rate was still high. Although it decreased $\mathrm{Bcl}-2$ expression, the degree of reduction was limited; tumor cells still expressed $\mathrm{Bcl}-2$ at a high level. In this experiment, whether or not $\mathrm{Bcl}-2$ expression is altered due to the length of transfection time was not tested. Other apoptotic proteins were not tested, this is an additional limitation of our study. Therefore, further studies are needed to make siRNA transfection more efficient, possibly through the exploration of more appropriate transfection vectors, transfection approaches and transfection timings.

\section{Acknowledgements}

The present study was supported by Science and Technology Fund of Shaanxi Province (no. 2008K09-05) and the National Natural Science Foundation of China (no. 30971340).

\section{References}

1. Lai CH and Lau WY: Gallbladder cancer - a comprehensive review. Surgeon 6: 101-110, 2008.

2. Zhu AX,Hong TS, Hezel AF and Kooby DA: Current management of gallbladder carcinoma. Oncologist 15: 168-181, 2010.
3. Miller J and Jarnagin WR: Gallbladder carcinoma. Eur J Surg Oncol 34: 306-312, 2008.

4. Pelengaris S, Khan M and Evan GI: Suppression of Myc-induced apoptosis in beta cells exposes multiple oncogenic properties of Myc and triggers carcinogenic progression. Cell 109: 321-334, 2002.

5. Mikami T, Yanagisawa N, Baba H, Koike M and Okayasu I: Association of Bcl-2 protein expression with gallbladder carcinoma differentiation and progression and its relation to apoptosis. Cancer 85: 318-325, 1999.

6. Quan ZW, Wu K, Wang J, Shi W, Zhang Z and Merrell RC: Association of p53, p16, and vascular endothelial growth factor protein expressions with the prognosis and metastasis of gallbladder cancer. J Am Coll Surg 193: 380-383, 2001.

7. Goldin RD and Roa JC: Gallbladder cancer: a morphological and molecular update. Histopathology 55: 218-229, 2009.

8. Shaffer EA: Gallbladder cancer: the basics. Gastroenterol Hepatol 4: 737-741, 2008.

9. Weyhenmeyer B, Murphy AC, Prehn JH and Murphy BM: Targeting the anti-apoptotic Bcl-2 family members for the treatment of cancer. Exp Oncol 34: 192-199, 2012.

10. García-Sáez AJ: The secrets of the Bcl-2 family. Cell Death Differ 19: 1733-1740, 2012.

11. Sasatomi E, Tokunaga $\mathrm{O}$ and Miyazaki K: Spontaneous apoptosis in gallbladder carcinoma. Relationships with clinicopathologic factors, expression of E-cadherin, bcl-2 protooncogene, and p53 oncosuppressor gene. Cancer 78: 2101-2110, 1996.

12. Meister G and Tuschl T: Mechanisms of gene silencing by double-stranded RNA. Nature 431: 343-349, 2004.

13. Fjose A, Ellingsen S, Wargelius A and Seo HC: RNA interference: mechanisms and applications. Biotechnol Annu Rev 7: 31-57, 2001.

14. Maurya SK, Tewari M, Mishra RR and Shukla HS: Genetic aberrations in gallbladder cancer. Surg Oncol 21: 37-43, 2012.

15. Kuroki T, Tajima Y, Matsuo K and Kanematsu T: Genetic alterations in gallbladder carcinoma. Surg Today 35: 101-105, 2005.

16. Tsujimoto Y, Finger LR, Yunis J, Nowell PC and Croce CM: Cloning of the chromosome breakpoint of neoplastic B cells with the $t(14 ; 18)$ chromosome translocation. Science 226: 1097-1099, 1984.

17. Mello CC and Conte D Jr: Revealing the world of RNA interference. Nature 431: 338-342, 2004.

18. Tyner $\mathrm{J}$ and Druker BJ: RNAi screen for therapeutic target in leukemia. Cell Cycle 8: 2144, 2009.

19. Lima RT, Martins LM, Guimarães JE, Sambade C and Vasconcelos MH: Specific downregulation of bcl-2 and xIAP by RNAi enhances the effects of chemotherapeutic agents in MCF-7 human breast cancer cells. Cancer Gene Ther 11: 309-316, 2004. 